\title{
Guidelines for Authorship Credit, Order, and Co-Inquirer Learning in Collaborative Faculty-Student SoTL Projects
}

\section{ABSTRACT}

Determining authorship credit and order in collaborative research projects can be difficult, can introduce or increase conflict in the research environment, and can exacerbate existing inequalities and affect power dynamics between team members. As a result, much disciplinary scholarship has been written to develop potential guidelines for authorship credit and order. However, the collaborative interdisciplinary nature of much SoTL work, along with the increasing focus of SoTL on students as co-inquirers into SoTL research, creates unique issues and challenges in ethically assigning authorship credit on SoTL projects. Informed by seminal disciplinary papers on authorship issues and best practices in undergraduate research, this paper proposes a new model to identify the relative contributions of student collaborators and explicitly incorporate a process-focused approach to collaborative faculty-student SoTL projects.

\section{KEYWORDS}

authorship credit, authorship order, faculty-student collaboration, students as co-inquirers

Determining authorship credit and order in collaborative research projects has been the subject of much disciplinary debate in higher education (Fine \& Kurdek, 1993; McGlynn, 2015; Winston, 1985; Zare, 2014), and conflicts between collaborators over authorship are not uncommon (Sandler \& Russell, 2005). For SoTL scholars, many of whom engage in interdisciplinary research, the problem becomes even more acute because there are no established guidelines for working across disciplines (Nguyen \& Nguyen, 2006). Further, SoTL has increasingly embraced involving students, especially undergraduates, as co-inquirers into SoTL scholarship (Bovill, Cook-Sather, \& Felten, 2011; Felten, 2013; Felten, Bagg, Bumbry, Hill, Hornsby, Pratt, \& Weller, 2013), and research collaborations between faculty and students involve unique inequalities and power dynamics (Fine \& Kurdek, 1993; Thompson, 1994). Additionally, unlike Boyer's (1990) other three scholarships (i.e., discovery, integration, and application), SoTL is uniquely focused on research into student learning. This necessitates attention not only to the final disseminated product of the SoTL project and what that product tells us about student learning, but also attention to the process of the scholarship (Gilpin, 2009), and what the student coinquirers learn from conducting the scholarship. By focusing only on authorship guidelines, we might obscure a very important part of the learning process for the students actually engaging in the scholarship.

This piece proposes to address these issues. First, I review the benefits of scholarly collaborations with students for both students and faculty. Next, I discuss student perspectives on authorship and how they contrast with faculty perspectives. Third, I outline special issues in collaborating with students. Fourth, I present multiple existing disciplinary guidelines and models for authorship credit and order. Fifth, I propose a new set of guidelines for best practices in collaborating 
with students on SoTL projects, including determining authorship credit and order. Finally, I outline limitations of the proposed guidelines and directions for future research.

\section{Benefits of scholarly collaborations with students \\ Benefits to students}

As Felten (2013) notes, "The first principle of SoTL, of course, is inquiry focused on student learning" (p. 122). With student learning at the heart of all SoTL inquiry, one of the most important benefits of scholarly collaborations with students on SoTL projects is the increased potential for learning on the part of the student collaborators. Brew (2013) argues that pedagogies of student research must focus "primarily on students' learning" (p. 609). Extending this line of thinking, Garbati and Samuels (2013, p. 358) state, "Collaboration fits well with constructivist theories of learning .... In effective collaborative projects, a form of peer teaching takes place in which expertise is shared and creativity nourished." This is echoed by Wray (2006, p. 508) who asserts, "collaborative research plays an important role in the training of young scientists... [who] often learn the norms of science from working closely and collaboratively with mentors who are established in their field." I would argue that the benefits Wray describes are not limited to the sciences or even to fields that predominantly use positivist epistemologies. Indeed, recent work has called attention to the importance of recognizing and respecting different disciplinary approaches to SoTL, including the need and value for both quantitative and qualitative approaches (Chick, 2013; Gurung, 2014), and students in all fields could benefit from this type of scholarly collaboration.

Nguyen and Nguyen (2006) report that scholarly collaborations with students provide students with unique opportunities to become excited about learning, though Healey, Flint, and Harrington (2014) note that such opportunities to become involved in faculty research are often reserved for only a handful of students. Additionally, such opportunities help students build resumes, gain new skills, expand and further their careers and post-graduate educational opportunities, and increase their autonomy (Kinkead, 2010; Nguyen \& Nguyen, 2006).

Scholarly collaborations on SoTL projects also offer students the ability to forge partnerships with faculty outside of the typical student-teacher relationship and in which the relationship between students and faculty can be fundamentally different (Bovill et al., 2011). Such collaborations can serve as a catalyst to change "students' relationships to their teachers and their responsibilities within their learning" (Cook-Sather \& Alter, 2011, p. 37). Further, in scholarly collaborations that offer meaningful partnership with student researchers, power dynamics are fundamentally altered and students have greater autonomy to act and a greater sense of responsibility (Manor, Bloch-Shulman, Flannery, \& Felten, 2010). In some cases, it is even possible for students to define or have input into the research problem or question, the methodology, and/or the means and audience for dissemination (Brew, 2013; Healey et al., 2014).

\section{Benefits to faculty}

Brew (2013) observed that, as approaches to integrating research experiences throughout the curriculum have increased, individual faculty may not have the authority to engage students in research in the classroom in the ways those faculty want to, focusing on the skills or levels of student autonomy faculty believe are most appropriate. However, collaborative research with students on SoTL that is conducted outside of curricular mandates could preserve faculty members' autonomy in these areas and give them the flexibility to design collaborative experiences as they see fit. From such collaborative research, faculty can develop new skills or improve existing ones, and such collaborations encourage 
sharing of information and provide opportunities to experience different perspectives (Nguyen \& Nguyen, 2006). This last benefit is especially important to SoTL with its frequent interdisciplinary projects and explicit attempts to avoid disciplinary "silo-ing” of scholarship. The burgeoning SoTL literature on students as partners and co-inquirers frequently discusses the benefit to faculty of hearing and learning from student perspectives on teaching and learning topics (Felten et al., 2013; Manor et al., 2010; Otis \& Hammond, 2010; Werder, Thibou, \& Kaufer, 2012; Werder, Ware, Thomas, \& Skogsberg, 2010) and suggests that such partnerships can enlarge the range of topics investigated (Manor et al., 2010). Finally, perhaps the most pressing reason to collaborate with students on SoTL projects is that partnership into inquiry with students is a basic element of good practice in SoTL (Felten, 2013), and collaboration is one form of such partnerships.

\section{Student perspectives on authorship}

The existing data on student perspectives on authorship is limited, which may itself be evidence of the student-faculty power differential on the issue of authorship credit. Neither the burgeoning literature on students as partners and co-inquirers in SoTL (Bovill et al., 2011; Felten et al., 2013; Healey et al., 2014; Manor et al., 2010; Otis \& Hammond, 2010; Werder et al., 2012; Werder et al., 2010), nor the broader literature on undergraduate research cited in the SoTL literature (e.g., Brew, 2006, 2013; Healey, 2005; Healey \& Jenkins, 2009) provides student perspectives on authorship in collaborative projects.

Outside the SoTL literature, only two studies are of note. A survey of faculty and graduate students in Psychology revealed that most graduate students believed in an objective vs. a relative standard for authorship and that, "authorship credit should be determined on the merits of professional contribution in all cases, regardless of competence” (Bartle, Fink, \& Hayes, 2000, p. 785). That is, students - with less knowledge, training, resources, and abilities — should be judged by the same standards as faculty members. The tasks that these graduate students determined to be the most worthy of authorship were writing the manuscript followed by developing the project ideas and the research design. In contrast, status, seniority, and data collection were viewed as unimportant to determining authorship.

Marusic, Bosnjak, and Jeroncic (2011) conducted a systematic literature review and limited meta-analysis of research published on the issue of authorship credit. Their summary of the literature on student perspectives suggested that students put significantly higher authorship value on research tasks that are usually given to students: collection of qualitative data, data entry, statistical analyses, writing the literature review or methods sections, and total time spent. In contrast, Marusic et al. reported that, across over 100 studies of faculty perspectives on authorship, there was a common perception that ideas, the research design, and writing the manuscript were most important contributions for authorship, similar to the findings reported by Bartle et al. (2000). It should be noted, then, that not only is there a potential conflict between what students and faculty believe to be deserving of authorship credit, but that the tasks that faculty typically believe are worthy of authorship credit are the tasks typically initiated by faculty due to their greater knowledge, expertise, training, and resources. If authorship credit is reserved for idea generation, research design, and manuscript writing, many students, especially undergraduate students, would be ineligible for significant credit even in fairly collaborative projects.

\section{Special issues in collaborating with students}

Collaborative research with students, especially undergraduates, presents three interrelated special issues that need to be considered. First, there is the question of why faculty want to engage in 
collaborative scholarship with students (beyond the desire to create partnerships with students or that it is a best practice in SoTL, noted above), and how those motivations may influence the collaborative process.

As Brew (2013) notes, the motivation to involve undergraduates in research may be driven by, "a desire to focus on the processes of engaging with research or alternatively getting students to produce some kind of research outcome" (p. 610). Though not mutually exclusive, these two foci are significantly different, and it is important to recognize and value both in SoTL (Gilpin, 2009). Indeed, the primary distinguishing feature between scholarly teaching and SoTL is the requirement for public dissemination of products for SoTL (McKinney, 2003). Levy, Little, and Whelan (2011) report that collaborative projects can vary substantially in the degree to which they focus on process-oriented skill development or product-oriented outcomes. Healey et al. (2014) observe that most published examples of students engaging in SoTL are "one-off projects" (p. 47), which may suggest a more product-oriented approach.

Childress (2015) argues that scholars should view "undergraduate research as a process, not an outcome" (p. 6). In this case, Childress is not referring exclusively to SoTL research, but all forms of research, and this view is common in the publications of the American Council on Undergraduate Research [CUR]. For example, Malachowski (2012) delineates key differences between productcentered and process-oriented models of scholarship. Product-centered scholarship focuses on scholarly results and especially publication or similar dissemination, but "the process of doing the work is minimized or wholly absent from faculty discussions" (p. 9). Such an approach, "can distance the faculty from their students and can have a negative impact on student learning" (p. 9). In contrast, "in the process-oriented model of research, both product and process are considered important, with undergraduate research serving as the best exemplar of this model. Engaging undergraduates in the research process can enhance student learning and student outcomes" (p. 10).

Willison and O'Regan (2007) have proposed a linear conceptual model of students' research skills that highlights the progression from solely process-oriented to process and product oriented:

At most levels of education, students research knowledge that is unknown to themselves, but which is commonly known to others... and typically takes the form of assignments that are prescribed by others. As a student's education progresses, their research moves into a discipline discourse with concepts, language and conventions unknown to those outside that discipline. Research, at this level, is into the commonly not known. As students become well acquainted with a canon of a discipline and its research techniques, they may be ready, probably at postgraduate level, to research gaps into or even extend the field into areas previously unknown to humankind. (p.399)

According to Malachowski (2012), faculty who take the process-oriented approach view students, "as partners in the intellectual process" (p. 12), which echoes Felten's (2013) principles of good practice in SoTL and the SoTL student partnership literature. Key to that literature is the premise that authentic partnership with students is contingent upon high levels of student autonomy in the collaborative process (Bovill et al., 2011; Healey et al., 2014; McKinney, Jarvis, Creasey, \& Herrmann, 2010; Sublett, Walsh, McKinney, \& Faigao, 2010; Temple, Sibley, \& Orr, 2010). As Brew (2006) describes:

Participation needs to be as an equal. I do not mean that everyone is equal in the sense of having equal skills and knowledge. Clearly, different members of any community will 
inevitably bring different skills and knowledge, and at different levels. My concept of equality here is about treating individuals as fully participating human beings with things to contribute as well as things to learn. (p. 34).

Thus, to achieve the significant levels of student autonomy necessary for authentic partnership in SoTL research collaborations, it is important to focus not only on what students have to contribute to the collaboration, but also on what they have to learn from that collaboration. This is especially important given that students often enter undergraduate research with a product-centered or taskoriented approach (Temple et al., 2010) similar to the surface-oriented approach to classroom learning that students sometimes take (Biggs, 1999; Prosser \& Trigwell, 1999). Faculty must explicitly encourage students to reflect on what they are learning from the process (Temple et al., 2010). Even if publication or similar dissemination is the "end goal" of the collaboration, a process-oriented approach will help to keep the focus on student collaborators' learning. For SoTL projects, which by definition already focus on student learning (Felten, 2013) and are inherently process-oriented (Gilpin, 2009), taking a processoriented approach to co-inquiring with student collaborators should represent nothing more complicated than simply broadening the definition of "learning" under investigation to include student collaborators' own learning from the process.

The second issue that needs to be considered when collaborating with students on SoTL projects is the reality of how faculty scholarship is evaluated in higher education. This issue overlaps with the first issue of product-centered vs. process-oriented approaches to such collaborations and has the potential to significantly influence decisions about which approach to take. Authoring scholarship (i.e., the product) has significant benefits to faculty careers including job retention, tenure, promotion, pay, grants, and annual reviews (Wilcox, 1998), but the process-oriented pieces are typically of little value. Additionally, faculty credit for scholarship in many fields decreases with authorship order and with number of authors, especially for decisions about promotion and tenure (Seipel, 2003). Thus, although it is in the interests of many faculty to produce authored scholarship, there can be clear disincentives to sharing authorship credit with student collaborators. Further, precisely because of the process-oriented nature of collaborating with undergraduate students, many students lack the skills, training, and abilities necessary to be immediately helpful to faculty scholarship. ${ }^{1}$ Faculty need to teach these skills to students and that can be quite time consuming, time that many faculty and especially junior faculty may not have (Maher, Timmerman, Feldon, \& Strickland, 2013). The "publish or perish" climate within many higher education institutions can also lead to junior faculty being disproportionately affected if student collaborators fail to complete assigned tasks (Stith, Barasch Jester, \& Linn, 1992).

Additionally, even if students complete all assigned tasks satisfactorily, those students may not be sufficiently motivated to pursue scholarly dissemination of the work. Stith et al. (1992) reported that faculty wanted to retain the option to be senior author on manuscripts based on student theses if the students were not interested in pursuing publication, suggesting this was not an uncommon occurrence. Oberlander and Spencer (2006) caution that faculty should use explicit timelines with students and that if students do not pursue publication by the established deadline, faculty should be free to do so. These issues suggest that, although it may be a best practice for faculty to take a process-oriented approach to collaborating with students on SoTL projects, faculty must also be mindful of the potential need to disseminate a product and establish clear guidelines and procedures for working with students to accomplish both goals.

It is the lack of such clear guidelines that focus on process but are mindful of product that is the third issue that needs to be considered in collaborating with students on SoTL projects. The student 
partnership literature has identified that collaborations with students may result in publication or other dissemination of the scholarship (Healey \& Jenkins, 2009), and is replete with examples calling for treating student collaborators as co-researchers or co-authors (Levy et al., 2011; Sublett et al., 2010). This literature has even identified problems in determining authorship credit and assigning authorship order (Kill, McDonnell, \& Thorne, 2011; Perrier, 2006; Sharp, Stanley, \& Hayward, 2011), yet it does not provide guidelines or criteria for how to determine if a student has merited authorship or what the order of authorship should be. Even undergraduate journals that require submissions to list an undergraduate as first author do not provide guidelines for determining authorship credit or order (Metcalfe, Gibson, \& Lambert, 2011; Spronken-Smith, Brodeur, Kajaks, Luck, Myatt, Verburg, Walkington, \& Wuethrick, 2013). It is clear, then, that what is needed is a model for determining authorship credit and order that also incorporates the process-oriented elements that are central to collaborative SoTL scholarship with students. The next section outlines existing disciplinary models for determining authorship credit and order.

\section{Existing guidelines and models}

Multiple sets of disciplinary guidelines and models exist for determining authorship credit and order, but none of them incorporates the process-oriented elements described above as the primary focus of student involvement in scholarship. This is not surprising given the academic reward structure's focus on product over process reviewed in the last section (Seipel, 2003; Wilcox, 1998). For the same reasons, it is not surprising that most of these guidelines and models do not even explicitly mention students as potential collaborators. Many of these disciplinary guidelines and models come from the natural sciences, are rigidly hierarchical, and often relegate to junior authorship the student who has actually done the most work on the project (Kill et al., 2011). Although none of these guidelines and models fully meet the needs for a model for collaborative SoTL scholarship as outlined above, they are nonetheless helpful to describe the current state of scholarship on these issues and to inform the development of the new needed model. Below, I describe four of the most widely used or commonly known guidelines and models.

The most widely used guidelines are those of the International Committee of Medical Journal Editors [ICMJE], which are used by over 500 journals worldwide (Davidoff, 2000). To qualify for authorship, a person must meet all four of the following criteria: (a) substantial contributions to the conception or design of the work; or the acquisition, analysis, or interpretation of data for the work; (b) drafting the work or revising it critically for important intellectual content; (c) final approval of the version to be published; and (d) agreement to be accountable for all aspects of the work in ensuring that questions related to the accuracy or integrity of any part of the work are appropriately investigated and resolved (International Committee of Medical Journal Editors, n.d.). However, these guidelines are not without criticism (Matheson, 2011; Moffatt, 2011), and examples where no one who worked on a project qualifies for authorship credit under this system have been revealed (Shaw, 2011). These guidelines also include no information on how to treat student collaborators differently.

Another set of widely used guidelines are those promoted by the American Psychological Association (2010). As APA style is the official citation style of Teaching \& Learning Inquiry: The ISSOTL Journal, and the only named style in the journal's instructions for authors, these guidelines are the closest thing to an "official" position on these issues for ISSOTL. These guidelines have two defining features: (a) "substantial contributions" and (b) "relative contributions." 
Authorship encompasses, therefore, not only those who do the actual writing but also those who have made substantial scientific contributions to a study. Substantial professional contributions may include formulating the problem or hypothesis, structuring the experimental design, organizing and conducting the statistical analysis, interpreting the results, or writing a major portion of the paper. (p. 18)

Further, "authorship should be determined by the relative contributions of student and faculty member to the project" (p. 19). However, the APA offers little guidance on what threshold is required to meet a "substantial" contribution or how to weigh a "relative" contribution, which leaves individual faculty members without clear guidelines. These guidelines also reflect a clear bias towards quantitative methodologies and positivist epistemologies, limiting their usefulness to many fields.

Winston (1985) attempted to provide quantifiable guidelines to assist faculty in identifying which contributions merited inclusion as an author and how to determine the order of authorship. His system is one of the most frequently cited quantifiable systems in the authorship literature, with nearly 50 citations. It used a "points system" for authorship wherein any manuscript could have a maximum of 272 possible points divided between the authors with specific points assigned for specific research tasks. Anyone who earned at least 50 points qualified for authorship and authorship order would be based on individuals' point totals.

Although the goal of trying to quantify specific contributions was laudable, multiple problems emerged from this approach. First, under this model it is not possible for any manuscript to have more than five authors. This artificially limits its utility to small research teams. Indeed, such guidelines would have disqualified from consideration for publication multiple articles published in Teaching \& Learning Inquiry: The ISSOTL Journal (e.g., Felten et al., 2013, Spronken-Smith et al., 2013). It is unrealistic to expect that SoTL collaborations, especially with students, would always be limited to teams of five or fewer people.

Second, the specific points assigned to each research task were based on the amount of time each task would take, with no allowance for differences between individuals in ability, competence, effort, efficiency, or thoroughness. Third, like the APA guidelines, there was a strong quantitative bias in the guidelines, which makes them inappropriate for qualitative or mixed-methods projects. Fourth, other point systems are possible (e.g., DiGiusto, 1994) and there is no clear rationale for why certain research tasks, like coming up with the idea, should be weighted more heavily than others, like writing the manuscript. Like the ICMJE guidelines, these guidelines also include no information on how to treat student collaborators differently.

Finally, Fine and Kurdek (1993) developed what is likely the most widely used set of guidelines specifically for working collaboratively with students, cited over 200 times. They identified the key issue in determining student authorship:

In the authorship setting, if students are not considered to be meaningfully different from professional colleagues, then they should be awarded authorship credit and order on the same basis as those of nonstudent colleagues. However, if one makes the contrasting assumption that students have less power and competence than nonstudent collaborators, then justice would be served by giving students differential treatment. (p. 1143)

Specifically, they argued for a relative standard for authorship (which was later adopted by the APA and reflected in their guidelines reviewed above): 
There should be a varying standard for the level of professional contribution that is required to attain a given level of authorship credit. Because collaborators differ in their scholarly expertise, their competence to contribute professionally to scholarly publications should be viewed as lying along a continuum. On one end of the continuum are collaborators who have limited competence in scholarly activities and who require intensive supervision. On the other end are collaborators who have considerable competence in scholarly endeavors and who function independently... the level of contribution expected of a collaborator should depend on where he or she falls on this competence continuum. For the same level of authorship credit, one should expect greater professional contributions from collaborators who have more competence than from those who have less competence. (pp. 1144-1145)

Fine and Kurdek created a four-step model in which faculty and students should negotiate together: (a) early on, the faculty member discusses with the student information about how authorship decisions are made and the nature of different types of contributions, (b) assess the abilities of each collaborator, the research tasks that need to be done, the amount of supervision required, and the expectations for each collaborator, (c) discuss and agree on which tasks and contributions are required for each collaborator to merit authorship and order, and $(\mathrm{d})$ revisit and renegotiate agreements as the project changes or as feedback is received during the manuscript revision process. Fine and Kurdek also suggest that Winston's (1985) points model may be helpful in particularly complicated situations, but that it would need to be weighted to reflect the relative scholarly competence of each collaborator. However, they provide no guidelines for specifically how to weight Winston's model. Although the Fine and Kurdek (1993) guidelines provide an excellent general approach, their lack of clearly establishing how to define "relative" contributions in an objective or quantifiable way limits their utility.

Evaluating the four sets of guidelines together, three key shortcomings emerge: a) there is a strong bias towards quantitative research and positivist epistemologies, b) two of the sets of guidelines make no mention of student collaborators at all and the two sets that do discuss student collaborators both fail to specify precisely how to determine the relative value of student contributions, and c) all four sets of guidelines leave out the process-oriented piece that is so central to SoTL scholarship and to collaborating with students on scholarship. What is needed is a process-oriented model that provides guidelines for authorship credit and order as well as a focus on student co-inquirers' learning. This model should specify how to determine the relative value of student contributions and be applicable to a wide variety of research methods and epistemologies. In the next section, I present one possible model to address these issues.

\section{Towards a process-oriented model}

As noted by Willison and O'Regan (2007), most student inquiry—research or not—will be more about process than about product, especially at the early levels (Childress, 2015; Gilpin, 2009; Malachowski, 2012; Temple et al., 2010). The challenge for collaborative faculty-student SoTL projects then becomes how to balance the process-oriented piece that focuses on the student collaborators' learning and skill development with the product-oriented reality of higher education (and the genuine desire to share the results of our scholarship with the broader SoTL community). One potential answer to that challenge is to integrate the process-oriented focus exemplified by the American Council on Undergraduate Research with some of the product-oriented guidelines reviewed above (also mostly 
American). Perhaps ironically, a framework for conceptualizing research skills proposed by Australians Willison and O'Regan (2007) may provide the best way to do this.

Willison and O’Regan (2007) developed the Research Skill Development Framework (Appendix), which they have subsequently expanded and refined into the Researcher Skill Development [RSD] Framework (Willison \& O’Regan, 2006/2013). In this framework, all research-regardless of discipline or type —is described as having six equal major facets: (a) Embark \& Clarify, (b) Find \& Generate, (c) Evaluate \& Reflect, (d) Organise \& Manage, (e) Analyse \& Synthesise, and (f) Communicate \& Apply Ethically. Each facet has seven levels of researcher autonomy: (a) Prescribed Research, (b) Bounded Research, (c) Scaffolded Research, (d) Researcher-initiated, (e) Open Research, (f) Adopted Research, and (g) Enlarging Research. See Figure 1. In this model, "autonomy" references the same concept as "competence" in the Fine and Kurdek (1993) model.

For any research project, it is possible to locate the project itself on one of seven levels for each of the six facets, and to specifically identify the level on each facet that any collaborator is performing. This Framework provides a way to easily identify the relative contributions of each collaborator as recommended by both Fine and Kurdek (1993) and the APA (2010), and maintain a focus on the process of research (Childress, 2015; Gilpin, 2009; Malachowski, 2012; Temple et al., 2010) and the primacy of student learning in SoTL research. Below, I outline one way to integrate this processoriented approach into existing product-oriented disciplinary guidelines to create a new set of guidelines for best practices, authorship credit, and authorship order in collaborative faculty-student SoTL projects. To facilitate understanding of these guidelines, I provide a worked example from an ongoing collaborative SoTL project I am conducting with an undergraduate student.

However, before presenting these guidelines, I caution the reader that applying them too rigidly will fail to capture the complexity and fluidity of the collaborative research process. To help prevent a rigid application of these guidelines, I offer multiple methods for using the RSD framework to determine authorship (Step 4) and explicitly require ongoing revisiting of the process as the research unfolds (Step 5).

Step 1: At the start of the project, identify what level for each facet on the RSD Framework is required to bring the project to completion. This may be done exclusively by the faculty member(s), by the faculty member(s) with student input, or by the faculty member(s) and student(s) collaboratively, depending on the situation.

For my collaborative project, I designed and began the project before I had even met the undergraduate collaborator. I determined that the project would require autonomy at Level 5 for all six facets of the RSD Framework. However, upon adding the undergraduate collaborator, I revised Facet D to Level 6 to reflect the creation of a research team.

Step 2: Determine if the nature of the project is such that it is possible to involve students in the project and in what capacities: (a) If the project is such that students cannot be involved, shared authorship discussions are moot; (b) If student involvement will be process-oriented only (e.g., solely for the learning experience and either the project will not lead to dissemination or the ways in which students will be involved will not yield contributions to the final product), shared authorship discussions are not technically necessary, but would still represent a best practice because it would still be beneficial from a student learning perspective to proceed through the remaining steps and explain to students how such decisions are made. Additionally, it is necessary to engage in at least Steps 3 and 4 below to identify appropriate student learning objectives and tasks for their involvement in the project; (c) If student involvement will be both process-oriented and product-oriented (i.e., Malachowski's process-oriented model of research), proceed with Step 3. It should be noted that, for many projects, student involvement 
could be either $2 \mathrm{~b}$ or $2 \mathrm{c}$, or even some students participating in $2 \mathrm{~b}$ and some participating in $2 \mathrm{c}$. In such cases, as part of Steps 3 and 4 below, it is important to involve the students themselves in the decisionmaking process to determine what type of experience they prefer and to clearly explain why some students would earn shared authorship credit, but others would not (Zare, 2014). It is also possible that over the course of the project, student involvement may shift from $2 \mathrm{~b}$ to $2 \mathrm{c}$ or vice versa and in such cases, it would be necessary to renegotiate Steps 3 and 4.

For my collaborative project, I had initially identified it as a $2 \mathrm{~b}$ opportunity for students to learn basic data entry and perhaps even limited data analysis skills. Because the project data collection window spanned more than three years, I thought it unlikely that a student would be involved in the project for long enough to see it through to dissemination. When I identified an undergraduate student who I thought might be interested in learning those skills (near the end of year two of data collection), I approached her with the opportunity. She agreed to assist me with the research for an academic year in exchange for Honors experiential learning credit. At the end of the academic year during which she would assist me, I would still be collecting data for another seven months, and only then begin final analyses and writing.

Step 3: Assess the skills and abilities of each collaborator (faculty and students) and what level of autonomy they possess on each of the 6 facets of the RSD Framework with special attention to the level of supervision and guidance required. From here, it should be possible to "map" student skills onto specific tasks or components of the project identified in Steps 1 and 2: (a) Because all student involvement in undergraduate research should have a process-oriented component, this "mapping" should not focus only on students' current skills and abilities. ${ }^{2}$ Explicit attention should be given to what new skills and abilities students will learn as part of their involvement in the research process (i.e., what the faculty member(s) or others will teach them). In other words, how will students' involvement in the project move them to the right - towards higher levels of research autonomy-on one or more of the six facets of the RSD Framework? This is the most important element of these guidelines; (b) It is not necessary to incorporate all six facets of the RSD Framework into students' involvement in the project. There are many cases where focusing on only one or two facets would be not only appropriate, but highly effective at teaching focused skills in greater depth (e.g., how to conduct a literature search, how to perform specific lab procedures, etc.). Additionally, it may be necessary or desirable to have different students working on different components of the project, which map to different facets; (c) Discuss with students the different options for learning new skills and abilities to identify which facets of the RSD Framework they are most interested in progressing through. What do they want to learn? If possible, try to "map" students onto tasks that most closely align with what they want to learn. Involving students in setting their own learning objectives for the inquiry experience is both uncommon and challenging, but represents a best practice in guiding student inquiry (Brew, 2006). This also links back to Step 2c.

The descriptors of the levels of autonomy in the RSD Framework are intentionally broad so as to be applicable to a wide range of disciplines and situations. However, this also necessitates that in "mapping" the students onto project tasks, specific, measurable criteria be established so that it is possible to objectively determine if the student has achieved that level of autonomy. This will reduce the possibility of later disagreement over whether or not the student has achieved the level of autonomy planned at this step. Although the criteria used will vary not only from discipline to discipline, but even project to project, the process should remain the same. For example, if the student were mapped to learn to perform at F2, which requires the use of "discipline-specific language" to demonstrate understanding, a list of key terms or concepts that the student should be able to use correctly could be created and the student's written or oral presentations could be examined for the use of such terms or concepts. 
For my collaborative project, I had already completed SoTL research at Level 5 or above on all six facets before the project began. The student had been in a year-long research class with me the prior year, and on that basis we mapped her skills on the RSD Framework as: A2, B3, C2, D2, E1, and F3. I explained to her that my major need for assistance with this project was with quantitative data entry, but that there were also opportunities for me to teach her about some forms of quantitative data analysis, and if she were interested, for her to present her work at various undergraduate conferences and symposia. We discussed what she was most interested in learning about, and agreed that because she was least autonomous and had the most room for learning and growth in Facet E, and to a lesser extent Facet $\mathrm{C}$, those would be the areas we would focus on for her involvement in the project. I would teach her basic quantitative data entry skills and basic quantitative data analyses, with the goal that by the end of the project she would have achieved C3 and E5. She also expressed an interest at presenting her work, so we mutually identified 2-4 options from a larger list of seven possible opportunities. All of the presentation opportunities she selected allowed undergraduates to present research conducted under faculty mentorship as sole author, with the mentor acknowledged in the presentation.

Some of the objective criteria we developed to evaluate her performance were: a) all data from the questionnaire forms would be entered correctly into the electronic database by a target date, $b$ ) she would be able to correctly replicate and interpret data analyses I had performed, c) she would submit applications to at least two of the presentation opportunities we identified, and d) she would deliver her presentation at any venue that accepted it.

Step 4: Discuss with collaborators the nature of different types of contributions, the difference between process-oriented only vs. process-oriented and product-oriented contributions, and agree on what tasks/contributions are required of each party to merit authorship and order. As part of this conversation, explicitly discuss the need for all collaborators to complete tasks on time and at what point a collaborator can be demoted or dropped from authorship for failure to complete tasks. Although not required, it is preferable if this agreement is in writing for the protection of all parties and to allay any concerns that faculty may have about student failure to complete tasks delaying their research. As Fine and Kurdek (1993) argue, "students have less power and competence than nonstudent collaborators" (p. 1143), so the threshold to justify shared authorship credit for student collaborators should be relatively lower. To visualize the relative contributions of student collaborators, "map" their contributions to the project onto the RSD Framework.

From this "mapping," there are multiple methods by which to determine authorship credit. I propose several, with the recommendation that faculty select the most appropriate method(s) on a project-by-project and student-by student-basis (i.e., just as holding students of different ability levels to the same objective standard would be problematic, so too would be automatically using the same method for a novice undergraduate student and an advanced graduate student): (a) if the student has demonstrated the increase in researcher autonomy planned in 3a (i.e., has moved at least as far to the right on each of the agreed-upon facets of the RSD Framework as planned), the student has earned authorship credit. Such a student collaborator has performed not only at their relative level of ability, but has increased their autonomy as a researcher in the process; (b) if the student has demonstrated autonomy at level four (i.e., Researcher-initiated) or higher on any of the six facets, the student has earned authorship credit. Level four of autonomy is the demarcating point between supervisor initiated and researcher initiated activities in the RSD Framework and represents the minimum level of autonomy that would typically be required to conduct independent publishable scholarship; (c) if necessary, a summative "point system" can be incorporated into the RSD Framework, with each level of autonomy equal to the number of its level (e.g., level four equals four points). In this way, performance 
at the lower levels of autonomy - where students are most likely to be-is valued equally with performance at the higher levels, maintaining the relative standard of evaluation. The total points for a project can be calculated at Step 1 based on the requirements to bring the project to completion, and faculty and students can mutually negotiate the number of points necessary to achieve authorship credit. For each collaborator, their contributions are "mapped" onto the RSD Framework (both at the start of the project, for clarity, and at the conclusion; see Step 5) and points are assigned. Authorship order can be determined in descending order based upon total points and can be applied even if method $4 \mathrm{a}$ or $4 \mathrm{~b}$ was used to establish authorship credit.

For my collaborative project, shared authorship credit was not initially discussed with the student because she was joining the project mid-way and would be finishing her involvement before the project end date. Instead, given the focus of the project on process-oriented student involvement (2b), we discussed opportunities for her to be the sole author in presenting her work at undergraduate research conferences and symposia. We discussed that, after her involvement with the project had ended, I would proceed with the research on my own and when finished would likely seek publication of it as sole author. It should be noted that, although the student would have met the criteria for authorship under $4 \mathrm{a}$ (or potentially $4 \mathrm{~b}$, if she had performed independent statistical analyses after learning how to do them), because her involvement was planned as process-oriented only ( $2 \mathrm{~b})$, was scheduled to end before the completion of the project, and alternative opportunities to present the work were identified, shared authorship credit was not part of our discussion.

Step 5: Mutually renegotiate agreements as the project changes, as students progress in their level of autonomy, or as feedback is received during the presentation/manuscript revision process. Whenever possible, encourage students to explicitly reflect on the research process and the skills and abilities they are learning.

For my collaborative project, the student has thus far met most of the RSD Framework progression goals and has met all goals on time (the project is ongoing). However, after only a few months working on the project, she expressed increasing interest in the project and repeatedly stated that she had become "invested" in the project. During our discussions about the research process and what she was learning, she began hypothesizing about what we might find in the results and why. After the data analyses for the first wave of data collection were completed and we saw the results, she began hypothesizing about why we might have observed those results, what we might have missed or done wrong in our administration of the project, and possible next steps for the project. It became clear to me that she was becoming more involved in, and contributing more to, this project than either of us had originally anticipated. After she had submitted the work for presentation at a national undergraduate research conference, I decided to revisit the issue of shared authorship with her.

I discussed that I had originally not broached the issue of shared authorship with her because she was coming on to the project after it had already been underway for two years and would continue for at least seven months past her agreed-upon end date. However, it appeared to me that she did not want to end her involvement with the project at the agreed-upon date anymore and I wanted to offer her the opportunity to continue with the project the next year. She very enthusiastically agreed with my assessment, so we began the shared authorship discussion anew, shifting from $2 \mathrm{~b}$ to $2 \mathrm{c}$. We renegotiated Steps 3 and 4 to create opportunities for her to become involved in new aspects of the project that would target different facets in the RSD Framework (A5 and F5). These opportunities would specifically focus on co-writing, allowing for her perspective as a student and her voice as a co-inquirer to "come out" in any disseminations. We discussed the contributions we would each make to the project and mutually agreed that since I had already contributed, and would contribute, significantly more to the project 
based on the RSD framework that I would be first author and she would be second author on any future disseminations. We anticipate both future presentations and publication of this project.

\section{Limitations and future directions}

The guidelines provided here suggest multiple ways to equitably determine shared authorship credit and order in collaborative faculty-student SoTL projects while also maintaining a focus on the process-oriented nature of both SoTL and mentored research. However, two important limitations must be noted.

First, the RSD framework was not initially created to reconcile authorship issues, but instead to provide a model for recognizing and cultivating researcher autonomy. I have adapted the RSD framework to this new purpose, with permission from John Willison, to extend its utility and help provide a way for SoTL-active faculty to approach authorship issues with an explicit focus on student researcher autonomy. Nonetheless, the proposed guidelines go "beyond" what the RSD framework was designed to do and no prior examples of it being used for authorship criteria exist in the literature. The closest similar documented use is of a collaborative faculty-student SoTL project that used the RSD framework to document that the student moved along the framework towards greater autonomy during the project, but with no description of how that was assessed or any specific plan to use it to inform authorship decisions (Delpish, Darby, Holmes, Knight-McKenna, Mihans, King, \& Felten, 2010). The guidelines proposed here represent the first known attempt to use the RSD framework to facilitate authorship decisions. Future worked examples of using the RSD framework to determine authorship credit and order would be helpful.

Second, although the guidelines presented here provide a mechanism for getting all parties involved to work out an explicit agreement about authorship issues, the power imbalance and inequalities in the faculty-student relationship will not be automatically resolved merely though the application of the guidelines. Pressures on faculty to publish — and as lead or sole author-are driven by much larger institutional, disciplinary, national, and economic forces; faculty ignore those pressures at their peril. However, the SoTL community is ultimately responsible for setting its own norms of practice, and it has already articulated as a "best practice" conducting SoTL in partnership with students (Felten, 2013; cf. Teaching \& Learning Inquiry: The ISSOTL Journals own review guidelines). This partnership fundamentally challenges traditional power dynamics (Bovill et al., 2011, Cook-Sather \& Alter, 2011; Manor et al., 2010) and this challenge has profound implications for authorship credit. If SoTL community leaders, like ISSOTL or leading interdisciplinary SoTL journals and conferences, were to adopt the authorship guidelines proposed here, that would send a strong message that shared authorship with students is not only appropriate but valued in SoTL scholarship. Although this may not change other sources of pressure on faculty to publish as lead or sole author, it would give faculty some "cover" to at least make an argument that their work is consistent with best practices and disciplinary norms.

In addition to these limitations, two issues in this area of research also need further exploration by SoTL scholars. First, existing research identifying student perspectives on authorship issues, especially undergraduate student perspectives, is extremely limited. Further, none of this literature explores student perspectives on authorship issues in SoTL research. Given the burgeoning literature on students as partners or co-inquirers in SoTL (Bovill et al., 2011; Felten et al., 2013; Healey et al., 2014; Manor et al., 2010; Otis \& Hammond, 2010; Werder et al., 2012; Werder et al., 2010), and the definitional requirement that SoTL be publicly disseminated (Potter \& Kustra, 2011; McKinney, 2003, 
2006, 2007), it seems incumbent on SoTL scholars to explore student perspectives on authorship issues in SoTL research. Such perspectives could help to inform and revise the guidelines presented here.

Second, the broader literature on students' surface or task-oriented approaches to learning (Biggs, 1999; Prosser \& Trigwell, 1999) might be adapted to explore why students often initially take a task or product-focused approach to research (Temple et al., 2010). Perhaps it is because, as Healey et al. (2014) note, "Most examples of students undertaking SoTL are one-off projects." (p. 47). The nature of the project itself may influence both student and faculty attitudes, and if the focus of the project is on remediation of a classroom "problem" instead of ongoing investigation into teaching and learning (Bass, 1999), this may encourage focus on product over process. Additionally, adapting this literature may help to reveal the circumstances under which faculty can help students shift to more process-oriented approaches. It is possible that findings from such research might also help to inform or revise the guidelines presented here, particularly with respect to Steps 2-4.

It is my hope that the guidelines presented here, and the issues outlined in this paper, will help further the discussion about students as partners, co-inquirers, and especially co-authors. As the SoTL community works to recognize student voices in disseminated work, we must find ways to value, in the words of Brew (2006), "the contributions of each person no matter what their level of prior understanding and knowledge" (p.163).

\section{ACKNOWLEDGEMENTS}

The author would like to thank John Willison for his feedback on an earlier draft of this manuscript, and the three reviewers for their extremely helpful suggestions. An earlier version of these guidelines were presented at the 2015 SoTL Commons Conference in Savannah, Georgia (US).

Trent W. Maurer is a Professor of Child \& Family Development in the School of Human Ecology at Georgia Southern University (USA).

\section{NOTES}

1. However, this presumes a "faculty-directed" approach to scholarship rather than a more equitable mutual collaboration on scholarly projects of mutual interest.

2. Although a process-oriented approach and learning new skills and abilities is also important for graduate students, there may be more cases where the existing skills and abilities of graduate students are sufficient to meet the needs of the project, especially if the students are already performing at the Researcher-initiated level of autonomy or higher. In such cases, it may not be possible within the scope of the project to focus on new skill acquisition.

\section{REFERENCES}

American Psychological Association. (2010). Publication manual of the American Psychological Association (6 ${ }^{\text {th }}$ Ed.). Washington, DC: American Psychological Association.

Bartle, S. A., Fink, A. A., \& Hayes, B. C. (2000). Psychology of the scientist: LXXX. Attitudes regarding authorship issues in psychological publications. Psychological Reports, 86, 771-788.

Bass, R. (1999). The scholarship of teaching: What's the problem? Inventio, 1(1).

Biggs, J. (1999). Teaching for quality learning at university. Buckingham, UK: SRHE \& Open University Press.

Bovill, C., Cook-Sather, A., \& Felten, P. (2011). Students as co-creators of teaching approaches, course design, and curricula: Implications for academic developers. International Journal for Academic Development, 16, 133-145.

Boyer, E. (1990). Scholarship reconsidered: Priorities of the professoriate. New York: The Carnegie Foundation for the Advancement of Teaching.

Brew, A. (2006). Research and teaching: Beyond the divide. Palgave Macmillan: New York, NY. 
Brew, A. (2013). Understanding the scope of undergraduate research: A framework for curricular and pedagogical decision-making. Higher Education, 66, 603-618.

Chick, N. L. (2013). Difference, privilege and power in the scholarship of teaching and learning: The value of the humanities in SoTL. In K. McKinney (Ed.), The scholarship of teaching and learning in and across disciplines (pp. 15-33). Bloomington, IN: Indiana University Press.

Childress, H. (2015). The outcomes are the outcomes: Making sure we assess what we actually care about. CUR Quarterly, 35 (3), 6-8.

Cook-Sather, A., \& Alter, Z. (2011). What is and what can be: How a liminal position can change learning and teaching in higher education. Anthropology and Education Quarterly, 42, 37-53.

Davidoff, F. (2000). Who's the author? Problems with biomedical authorship, and some possible solutions. Science Editor, 23(4), 111-119.

Delpish, A., Darby, A., Holmes, A., Knight-McKenna, M., Mihans, R., King, C., \& Felten, P. (2010). Equalizing voices: Student-faculty partnership in course design. In C. Werder \& M. M. Otis (Eds.), Engaging student voices in the study of teaching and learning (pp. 96-114). Sterling, VA: Stylus.

DiGiusto, E. (1994). Equity in authorship: a strategy for assigning credit when publishing. Social Science and Medicine, 38, 55-8.

Felten, P. (2013). Principles of good practice in SoTL. Teaching \& Learning Inquiry: The ISSOTL Journal, 1(1), 121125.

Felten, P., Bagg, J., Bumbry, M., Hill, J., Hornsby, H., Pratt, M., \& Weller, S. (2013). A call for expanding inclusive student engagement in SoTL. Teaching \& Learning Inquiry: The ISSOTL Journal, 1(2), 63-74.

Fine, M. A., \& Kurdek, L. A. (1993). Reflections on determining authorship credit and authorship order on facultystudent collaborations. American Psychologist, 48, 1141-1147.

Garbati, J., \& Samuels, B. (2013). Publishing in educational research journals: Are graduate students participating? Journal of Scholarly Publishing, 44, 355-372. doi: 10.3138/jsp.44-4-004

Gilpin, L. (2009). Reflective, reflexive, and recursive: The praxis of SoTL. MountainRise, 5.

Gurung, R. A. R. (2014). Getting foxy: Invoking different magesteria in the scholarship of teaching and learning. Teaching \& Learning Inquiry: The ISSOTL Journal, 2(2), 109-114.

Healey, M. (2005). Linking research and teaching exploring disciplinary spaces and the role of inquiry-based learning. In: Barnett, R. (Ed.) Reshaping the university: New relationships between research, scholarship and teaching (pp. 30-42). Maidenhead: McGraw-Hill/Open University Press.

Healey, M., Flint, A., \& Harrington, K. (2014, July). Engagement through partnership: Students as partners in learning and teaching in higher education. York, United Kingdom: The Higher Education Academy.

Healey, M., \& Jenkins, A. (2009, June) Developing undergraduate research and inquiry. York, United Kingdom: The Higher Education Academy.

International Committee of Medical Journal Editors. (n.d.). Defining the role of authors and contributors.

Kinkead, J. (2010). Advancing undergraduate research: Marketing, communications, and fundraising. Washington, D.C.: Council on Undergraduate Research.

Levy, P., Little, S., \& Whelan, N. (2011). Perspectives on staff-student partnership in learning, research and educational enhancement. In S. Little (Ed.), Staff-student partnerships in higher education (pp. 1-15). London, UK: Continuum International Publishing Group.

Maher, M. A., Timmerman, B. C., Feldon, D. F., \& Strickland, D. (2013). Factors affecting the occurrence of facultydoctoral student coauthorship. The Journal of Higher Education, 84,121-143.

Malachowski, M. R. (2012). Living in parallel universes: The great faculty divide between product-oriented and process-oriented scholarship. In N. H. Hensel \& E. L. Paul (Eds.), Faculty support and undergraduate research: Innovations in faculty role definition, workload, and reward (pp. 7-18). Washington, DC: Council on Undergraduate Research.

Manor, C., Bloch-Shulman, S., Flannery, K., \& Felten, P. (2010). Foundations of student-faculty partnerships in the scholarship of teaching and learning: Theoretical and developmental considerations. In C. Werder \& M. M. Otis (Eds.), Engaging student voices in the study of teaching and learning (pp. 3-15). Sterling, VA: Stylus.

Marusic, A., Bosnjak, L., \& Jeroncic, A. (2011). A systematic review of research on the meaning, ethics and practices of authorship across scholarly disciplines. PLOS ONE, 6 (9): e23477.

Matheson, A. (2011). How industry uses the ICMJE guidelines to manipulate authorship-And how they should be revised. PLoS Med, 8 (8): e1001072. 
McGlynn, T. (2015, February 27). The credit system in science is outdated. The Chronicle of Higher Education, p. A32.

McKinney, K. (2006). Attitudinal and structural factors contributing to challenges in the work of the scholarship of teaching and learning. In J. M. Braxton (Ed.), Analyzing faculty work and rewards: Using Boyer's four domains of scholarship-New directions in institutional research, \#129, (pp. 37-50). San Francisco: Jossey-Bass.

McKinney, K. (2003). What is the scholarship of teaching and learning (SoTL) in higher education? Teaching/Learning Matters, 33(1), 6-7.

McKinney, K. (2007). Enhancing learning through the scholarship of teaching and learning: The challenges and joys of juggling. San Francisco, CA: Jossey-Bass.

McKinney, K., Jarvis, P., Creasey, G., \& Herrmann, D. (2010). A range of student voices in the scholarship of teaching and learning. In C. Werder \& M. M. Otis (Eds.), Engaging student voices in the study of teaching and learning (pp. 81-95). Sterling, VA: Stylus.

Metcalfe, D., Gibson, C., \& Lambert, C. (2011). A collaborative foray into undergraduate publishing. In S. Little (Ed.), Staff-student partnerships in higher education (pp. 167-184). London, UK: Continuum International Publishing Group.

Moffatt, B. (2011). How authorship guidelines in Bioethics can ensure fairness and accountability. The American Journal of Bioethics, 11, 26-27.

Nguyen, T., \& Nguyen, T. D. (2006). Authorship ethics: Issues and suggested guidelines for the helping professions. Counseling and Values, 50, 208-216.

Oberlander, S. E., \& Spencer, R. J. (2006). Graduate students and the culture of authorship. Ethics \& Behavior, 16, 217-232.

Otis, M. M., \& Hammond, J. D. (2010). Participatory action research as a rationale for student voices in the scholarship of teaching and learning. In C. Werder \& M. M. Otis (Eds.), Engaging student voices in the study of teaching and learning (pp. 32-48). Sterling, VA: Stylus.

Perrier, M. (2006). Reflections on practicing student-staff collaboration in academic research: A transformative strategy for change? M/C Journal, 9(2).

Potter, M. K., \& Kustra, E. D. H. (2011). The relationship between scholarly teaching and SoTL: Models, distinctions, and clarifications. International Journal for the Scholarship of Teaching and Learning, 5(1), Article 23.

Prosser, M, \& Trigwell, K. (1999). Understanding learning and teaching: The experience in Higher Education. Buckingham, UK: SRHE \& Open University Press.

Sandler, J. C., \& Russell, B. L. (2005). Faculty-student collaborations: Ethics and satisfaction in authorship credit. Ethics \& Behavior, 15, 65-80.

Seipel, M. (2003). Assessing publication for tenure. Journal of Social Work Education, 39, 79-88.

Shaw, D. (2011). The ICMJE's definition of authorship is unethical. British Medical Journal, 343, 999.

Spronken-Smith, R. Brodeur, J., Kajaks, T., Luck, M., Myatt, P., Verburg, A., Walkington, H., \& Wuethrick, B. (2013). Completing the research cycle: A framework for promoting dissemination of undergraduate research and inquiry. Teaching \& Learning Inquiry: The ISSOTL Journal, 1(2), 105-118.

Stith, S. M., Barasch Jester, S., \& Linn, J. L. (1992). Student-faculty collaborative research. Family Relations, 41, 470474.

Sublett, M. D., Walsh, J. A., McKinney, K., \& Faigao, D. (2010). Student voices through researching and promoting learner autonomy. In C. Werder \& M. M. Otis (Eds.), Engaging student voices in the study of teaching and learning (pp. 146-161). Sterling, VA: Stylus.

Temple, L., Sibley, T. Q., \& Orr, A. J. (2010). How to mentor undergraduate researchers. Washington, DC: Council on Undergraduate Research.

Thompson, B. (1994). The big picture(s) in deciding authorship order. American Psychologist, 49, 1095.

Werder, C., Thibou, S., \& Kaufer, B. (2012). Students as co-inquirers: A requisite threshold concept in educational development? Journal of Faculty Development, 26(3) 34-38.

Werder, C., Ware, L., Thomas, C., \& Skogsberg, E. (2010). Students in parlor talk on teaching and learning: Conversational scholarship. In C. Werder \& M. M. Otis (Eds.), Engaging student voices in the study of teaching and learning (pp. 16-31). Sterling, VA: Stylus.

Wilcox, L. J. (1998). Authorship: The coin of the realm, the source of complaints. Journal of the American Medical Association, 280, 216-217.

Willison, J., \& O'Regan, K. (2006/2013). Researcher Skill Development Framework. 
Willison, J., \& O'Regan, K. (2007). Commonly known, commonly not known, totally unknown: A framework for students becoming researchers. Higher Education Research \& Development, 26, 393-409.

Winston, R. B., Jr. (1985). A suggested procedure for determining order of authorship in research publications. Journal of Counseling \& Development, 63, 515-518.

Wray, K. B. (2006). Scientific authorship in the age of collaborative research. Studies in the History and Philosophy of Science, 37, 505-514.

Zare, R. N. (2014). Scientific authorship: Giving credit where credit is due. Current Science, 106, 1171-1172.

Copyright for the content of articles published in Teaching \& Learning Inquiry resides with the authors, and copyright for the publication layout resides with the journal. These copyright holders have agreed that this article should be available on open access under a Creative Commons Attribution License 4.0 International (https://creativecommons.org/licenses/by/4.0). The only constraint on reproduction and distribution, and the only role for copyright in this domain, should be to give authors control over the integrity of their work and the right to be properly acknowledged and cited, and to cite Teaching \& Learning Inquiry as the original place of publication. Readers are free to share these materials-as long as appropriate credit is given, a link to the license is provided, and any changes are indicated. 